\title{
Considerações sobre a confissão e o método Reid aplicado na investigação criminal
}

\author{
Considerations of confessions and the \\ Reid Technique applied to criminal investigation
}

\section{Lívia Yuen Ngan Moscatelli ${ }^{1}$}

Universidade de São Paulo - São Paulo/SP, Brasil

liviamoscatelli@gmail.com

http://lattes.cnpq.br/5585348616715248

http://orcid.org/0000-0001-6163-841X

Resumo: O método Reid consiste na técnica de interrogatório mais difundida e utilizada em investigações criminais. Manipulação, persuasão, coerção e pressão psicológica são apenas alguns dos instrumentos utilizados em prol da confissão, pouco importando a sua veracidade. Esse estudo visa a esclarecer os seguintes questionamentos: Qual a principal herança proveniente do sistema processual penal inquisitório e como ela se relaciona com o interrogatório policial no Brasil? Quais são os principais motivos que podem explicar a incidência das falsas confissões? No que consiste o método Reid? Quais são as alternativas possíveis a essa metodologia?

Palavras-Chave: falsas confissões; interrogatório policial; método Reid; sistema inquisitório; verdade.

ABSTRACT: The Reid Technique is a method of interviewing and interrogation widely diffused and used in criminal investigations. Manipulation, persuasion, coercion and psychological pressure are just some of the instruments used in favor of confession, regardless of the veracity. This paper tries to clarify the

1 Mestranda em Direito na Universidade de São Paulo, no Departamento de Direito Processual, subárea de Processo Penal. Especialista em Direito Penal pela Faculdade de Direito da Universidade de Coimbra em parceria com o Instituto Brasileiro de Ciências Criminais (IBCCrim). Bacharela em Direito pela Universidade de São Paulo. Advogada em São Paulo/SP. 
following questions: What is the main inheritance from the inquisitorial criminal procedural system and how does it relate to the police interrogation in Brazil? What are the main reasons that can explain the occurrence of false confessions? What does the Reid Technique consist of? What are the possible alternative to this technique?

KEYWORDs: false confessions; police interrogation; Reid technique; inquisitorial system; true.

SUMÁRIO: 1. Introdução. 2. A tradição inquisitória e a valorização da confissão como rainha das provas; 3. Possíveis razões para a maior incidência de falsas confissões; 4 . O método Reid; 5 . O passo a passo da técnica interrogativa Reid; 6. Críticas ao método Reid e possíveis alternativas à metodologia; 7. Considerações Finais; Referências.

\section{INTRODUÇÃo}

Era noite de 19 de abril de 1989. Trisha Meili, advogada de 28 anos, corria dentro do Central Park, quando foi brutalmente atacada, estuprada e largada em estado de quase morte, com vestígios de sêmen em suas partes íntimas ${ }^{2}$. Após 12 dias, ela despertou de um coma profundo e não se recordava de nenhuma informação que pudesse esclarecer o bárbaro crime recém ocorrido. A vítima mal sabia, mas já nas primeiras 48 horas após ter sido violentada, a polícia de Nova Iorque já tinha obtido a declaração de cinco rapazes que teriam confessado a prática do crime: Antron McCray, Kevin Richardson, Raymond Santana, Yusef Salaam e Korey Wise. Eram adolescentes afro e hispano-americanos e possuíam de 14 a 16 anos $^{3}$.

Infelizmente, embora tal narrativa seja retratada em obra cinematográfica ${ }^{4}$, ela não é mais um dos roteiros de ficção criado para entreter e

2 KOEN, Wendy. Case Study: The Central Park five. In: KOEN, Wendy; BOWERS, C. Michael. The Psychology and Sociology of Wrongful Convictions. Academic Press. Londres, 2018. p. 332.

3 Ibid, p. 332-335.

4 Série "Olhos que condenam", produzida e divulgada pela Netflix em 2019. 
fixar a atenção do telespectador. Segundo Wyatt Kozinski, ela pode ser considerada a história real mais conhecida quando se trata da análise de falsas confissões ${ }^{5}$ extraídas a partir de técnicas de interrogatório. Submetidos ao escárnio da mídia, julgados e condenados a penas de $7 \mathrm{a}$ 13 anos $^{6}$, os cinco acusados foram presos injustamente, até que em 2002 o real autor do crime confessou a prática do delito e forneceu material genético para confrontação. Após a realização dos exames, foi constatado que Matias Reyes era o verdadeiro culpado pelo crime de estupro.

É exatamente durante as primeiras horas da investigação criminal que estes jovens deixam de ser meras testemunhas - que estavam no Central Park na noite em questão - e passam a ser investigados pela prática de um delito que não cometeram. Havendo uma atuação questionável por parte da Promotoria, que já tinha desde o início delineado a sua suposição acusatória e buscava a todo custo encontrar elementos para corroborar com a sua única hipótese inicial7, foi aplicado método de interrogatório Reid $^{8}$ para pressionar os jovens a criar uma narrativa já previamente construída: de que eles, sem ao menos se conhecerem,

5 Segundo Wyatt Kozinski, "O caso mais famoso deles é o do Central Park Five, onde os jovens do Harlem confessaram ter estuprado e espancando uma mulher que estava correndo pelo Central Park em Nova York. Mesmo que essas confissões fossem inconsistentes com as evidências físicas e o DNA no local não coincidir com qualquer um dos cinco, eles mesmo assim foram condenados". Tradução livre. KOZINSKI, Wyatt. The Reid Interrogation Technique and False Confessions: A Time for Change. Seattle Journal for Social Justice, Forthcoming, 2017. p. 15.

6 JOHNSON, Matthew. The Central Park Jogger Case-Police Coercion and Secrecy in Interrogation. Journal of Ethnicity in Criminal Justice, v. 3, 20, p. 131143, 2005.

7 "Quem investiga, segue uma [hipótese], às vezes com os olhos fechados; mas nada garante mais fundada em relação às alternativas possíveis, nem esse mister estimula cuidadosa autocrítica; como todas as cartas do jogo estão na sua mão e é ele que as coloca sobre a mesa, aponta a direção de 'sua' hipótese”. BADARÓ, Gustavo Henrique Ivahy. Epistemologia judiciária e prova penal. São Paulo: Thompson Reuters Brasil, 2019. p. 30.

8 Artigos e livros científicos que explicitam a utilização da metodologia Reid no emblemático caso do Central Park: GAVIN, Helen. Criminological and Forensic Psychology. Londres: Sage Publications Ltd., 2014. p. 253/254; JOHNSON, Matthew, op. cit; KOZINSKI, Wyatt, op. cit., p.15. 
teriam praticado em conjunto o crime sexual, ainda que inexistissem elementos informativos suficientes ${ }^{9}$.

Mesmo que não seja um problema adstrito a uma única localidade, o fenômeno das falsas confissões ficou mais conhecido a partir da experiência estadunidense. Dados apresentados pelo Innocent Project ${ }^{10}$, cuja causa se dedica à reversão de condenações injustas, indicam que as falsas confissões são, em sua maioria, feitas por jovens durante sua oitiva na Delegacia de Polícia. Ainda, o National Registry of Exonerations ${ }^{11}$ americano informou que, nos últimos 25 anos, $36 \%$ das condenações que foram revertidas após análise de DNA estavam respaldadas em falsas confissões feitas por menores de 18 anos, enquanto esse número incidiu somente em $10 \%$ para os adultos. Sob o viés intelectivo, as falsas confissões chegam a $69 \%$ dos casos de pessoas que possuem algum distúrbio mental ou cognitivo ${ }^{12}$.

Vale dizer, no entanto, que esses números apenas exibem a "ponta do iceberg”, já que a maioria das falsas confissões acontecem em crimes que não deixam vestígios, sendo quase impossíveis de contraprovar ${ }^{13}$ em seu aspecto material. E muito embora suas proporções não sejam tão

9 JOHNSON, Matthew, op. cit, p. 340.

10 INNOCENT PROJECT. False confessions more prevalent among teens. Disponível em: <https://bit.ly/36hBKzM> Acesso em: 03 dez de 2019.

11 Trata-se de projeto elaborado em conjunto pela Universidade da Califórnia, Irvine Newkirk Center for Science \& Society e a Universidade de Michigan. Sua missão institucional se dedica à coleta, análise e divulgações de informações sobre todas as exonerações conhecidas de réus criminais inocentes nos Estados Unidos, de 1989 até o presente momento. O instituto publica suas histórias e fornece dados estatísticos on-line acessíveis e pesquisáveis sobre seus casos. Também realiza estudos empíricos do processo de exoneração e de fatores que levam às convicções falsas. THE NATIONAL REGISTRY OF EXONERATIONS. Our mission. Disponível em: <https://bit.ly/2LwXFeI> Acesso em: 04 dez de 2019.

12 THE NATIONAL REGISTRY OF EXONERATIONS. Table: Age and Mental Status of Exonerated Defendants Who Falsely Confess. Disponível em: <https://bit.ly/2YsUqtT> Acesso em: 04 dez de 2019.Neste mesmo sentido: INNOCENT PROJECT. False confessions more prevalent among teens. Disponível em: <https://bit.ly/36hBKzM> Acesso em: 03 dez. 2019.

13 LEO, Richard A. Police interrogation and suspect confessions: social science, law and public policy. Academy of Justice: a report on scholarship and criminal justice reform, Cambridge, n. 6, 2017. https://doi.org/10.1017/9781108354721.010 
conhecidas diante de uma considerável dificuldade em identificar estes casos, o fenômeno deve ser considerado enquanto importante fator de risco de possíveis erros judiciais ${ }^{14}$.

Ao presente artigo, inicialmente buscar-se-á responder qual é a principal herança proveniente do sistema processual penal inquisitório e de que forma ela se relaciona com o interrogatório policial.

Em seguida, serão apresentadas as principais razões que podem explicar a incidência das falsas confissões. Também será explicitada a origem e a metodologia Reid, considerada como uma técnica coercitiva de interrogatório.

Ao final, serão tecidas críticas e apresentadas a metodologias investigativas alternativas, que se mostram mais compatíveis com uma investigação epistemicamente qualificada e que viabilize a proteção das garantias do interrogado.

\section{A TRADIÇÃO INQUISITÓRIA E A VALORIZAÇÃO DA CONFISSÃO COMO RAINHA DAS PROVAS}

Sob o prisma jurídico, historicamente é destinada uma importância especial à confissão. Desde os tempos primórdios e da tradição inquisitória, que tinha uma preocupação obsessiva e patológica com a busca pela "veritas"15, confessar significava a obtenção daquela verdade absoluta a ser arrancada do acusado a qualquer custo.

A descoberta dos fatos era uma preocupação adstrita ao segundo plano, já que a confissão era elevada ao patamar de rainha das provas ("confessio est regina probationum"16), inserida dentro da lógica do sistema

14 LAUDAN, Larry. Um ensayo sobre epistemología jurídica. trad. Carmen Vázquez y Edgar Aguilera. Madri: Marcial Pons, 2013. p. 33. Neste mesmo sentido, SILVA, Juliana Ferreira da. O plea bargain e as falsas confissões: uma discussão necessária no sistema de justiça criminal. Boletim IBCCRIM, São Paulo, v. 27, n. 318, p. 8-11., mai. 2019.

15 KHALED JR, Salah H. A busca da verdade no processo penal: para além da ambição inquisitorial. 2a Ed. Belo Horizonte: Casa do Direito, 2016. p. 64.

16 GASCÓN ABELLAN, Marina. Los hechos en el derecho: bases argumentales de la prueba. $3^{\text {a }}$ ed. Madri: Marcial Pons, 2010. p. 115. Neste mesmo sentido: COUTINHO, Jacinto Nelson de Miranda. O papel do novo juiz no processo 
legal de provas tarifadas ${ }^{17}$. A dinâmica, como explica Eugenio Zaffaroni, funcionava da seguinte forma: o sujeito de conhecimento (inquisidor) perguntava ao objeto de conhecimento (inquirido), a fim de colher a verdade. Se o objeto - vulgo sujeito - não desse uma resposta a contento, era violentado até a obtenção da resposta desejada ${ }^{18}$. Movido pelo desejo da dor passar, ao torturado restava apenas uma única defesa: a confissão, ainda que infundada e viciada.

Sobre a condução das perguntas formuladas pelo acusador e as negativas dadas pelo interrogado no sistema inquisitório, acertada é a síntese realizada por Nicolau Eymerich:

"Se o acusado continuar negando, e o inquisidor achar que ele omite seus erros - embora não haja provas -, intensificará os interrogatórios modificando as perguntas. Obterá, deste modo, ou a confissão, ou, então, respostas discrepantes. Se obtiver respostas discrepantes, perguntará ao acusado por que, de repente, responde de um jeito, e depois de outro: pressiona-o a dizer a verdade, explicando-lhe que, se não ceder, terá que ser torturado. Se confessar, tudo bem. Senão, isso bastará, juntamente com os outros indícios, para levá-lo à tortura e, desse modo, arrancar-lhe a confissão"19.

Nos tempos hodiernos, mesmo que o sistema jurídico brasileiro seja marcado pela Constituinte de 1988, a qual buscou delinear e assumir

penal. COUTINHO, Jacinto Nelson de Miranda (org.). In: Crítica à teoria geral do direito processual penal. Rio de Janeiro: Renovar, 2001. p. 52.

17 "A estrutura do processo inquisitório foi habilmente construída a partir de um conjunto de instrumentos e conceitos (falaciosos, é claro), especialmente o de "verdade real ou absoluta". Na busca dessa tal "verdade real", transforma-se a prisão cautelar em regra geral, pois o inquisidor precisa dispor do corpo do herege. De posse dele, para procurar a verdade real, pode lançar mão da tortura, que, se for "bem" utilizada, conduzirá à confissão. Uma vez obtida a confissão, o inquisidor não necessita de mais nada, pois a confissão é a rainha das provas (sistema de hierarquia de provas). Sem dúvida, tudo se encaixa para bem servir ao sistema”. PRADO, Geraldo Luiz Mascarenhas. Sistema acusatório. $3^{\mathrm{a}}$ Ed. Rio de Janeiro: Lumen Juris, 2006. p. 126.

ZAFFARONI, Eugenio Raúl. O inimigo do direito penal. Trad. Sérgio Lamarão. Rio de Janeiro: Revan, 2007. p. 38.

19 EYMERICH, Nicolau. Manual dos inquisidores. Rio de Janeiro: Rosa dos tempos, 1993. p. 125. 
o sistema acusatório ${ }^{20}$, somado ao recente artigo 3- $\mathrm{A}^{21}$ do Código de Processo Penal, além de outras previsões legais que limitam a utilização da confissão como único elemento probatório ${ }^{22}$, a confissão - seja ela verdadeira ou falsa - ainda permanece como peça principal da hipótese acusatória. Isso, dada a permanência de "uma doentia ambição pela verdade que se recusa arrefecer" ${ }^{23}$, pois o que interessa é o resultado, dentro de uma lógica puramente utilitarista ${ }^{24}$.

Realmente, até certo ponto é compreensível, já que o estímulo ao confessar parece ser um caminho mais fácil a ser percorrido, exigindo menor esforço intelectual, e, portanto, menor trabalho heurístico a ser empregado.

Diferentemente do procedimento adotado durante a ação penal, o interrogatório realizado durante a investigação criminal - em especial no inquérito, por ser a forma mais comum de apuração preliminar no Brasil - possui relevante papel para a formação da primária da culpa e do convencimento adotado pela Autoridade Policial.

Em pesquisa empírica conduzida por Michel Misse que avaliou inquéritos policiais de 5 capitais brasileiras ${ }^{25}$, observou-se que a confissão do

20 GRINOVER, Ada Pellegrini. Influência do Código de Processo Penal para Ibero-América na legislação latino-americana. Revista Brasileira de Ciências Criminais, São Paulo, v. 1, p. 542-574, 1993. p. 560.

21 CPP: “Art. $3^{\circ}$-A. O processo penal terá estrutura acusatória, vedadas a iniciativa do juiz na fase de investigação e a substituição da atuação probatória do órgão de acusação".

22 Vide o artigo 158 do CPP, que dita que "Quando a infração deixar vestígios, será indispensável o exame de corpo de delito, direto ou indireto, não podendo supri-lo a confissão do acusado", bem como art. 157 do mesmo diploma: "O valor da confissão se aferirá pelos critérios adotados para os outros elementos de prova, e para a sua apreciação o juiz deverá confrontá-la com as demais provas do processo, verificando se entre ela e estas existe compatibilidade ou concordância".

23 KHALED JR, Salah H. op. cit., p. 341.

24 Idem, p. 156-157. Além disso, a título exemplificativo, vale mencionar a epígrafe do recente livro "Técnicas de entrevista e interrogatório" em que se menciona que o objetivo da obra é "desvendar o oculto em busca da verdade real". MELO, Felipe Pereira de; BLANCHET, Luiz Renato; BITTENCOURT, José Cesar de. Técnicas de Entrevista e interrogatório. Curitiba: Intersaberes, 2019. p. 7.

25 A pesquisa foi conduzida nas cidades de Brasília, Rio de Janeiro, Porto Alegre, Recife e Belo Horizonte, com o objetivo compreender o papel e a função que o inquérito policial assume no processamento de crimes no Brasil. MISSE, 
suspeito foi mecanismo empregado em $80 \%$ das investigações, sendo realizadas poucas diligências externas e perícias técnico-científicas ${ }^{26}$, o que indica, sobretudo, o direcionamento da investigação em um aspecto que privilegia a prova ${ }^{27}$ testemunhal e a confissão em detrimento das outras. O perfil dos confessos nas Delegacias de Polícia, assim como no passado, continua sendo o das classes populares, especialmente quanto aos jovens vivendo em condições socioeconômicas precárias, de baixa escolaridade, pretos e pardos ${ }^{28}$.

Como bem apontou Joana Vargas, nas investigações de homicídios que são entendidas como bem-sucedidas, em geral a Polícia primeiro chega a um possível suspeito, extrai a sua confissão, para depois reconstituir a sua culpa ${ }^{29}$. A partir dela, é realizada uma seleção de quais outros elementos de informação deverão ser coletados.

Hipóteses são descartadas, cadeia de custódia das provas não são preservadas, outros suspeitos do crime não são ouvidos, perícias não são requeridas. Isto é, busca-se a todo custo a justificativa de uma única suposição, a partir das declarações extraídas que sustentem esta conclusão previamente já formulada em desfavor do suspeito, sendo esse fenômeno explicado por Franco Cordero, conhecido como o primado das hipóteses sobre os fatos ${ }^{30}$.

Michel. O inquérito policial no Brasil: uma pesquisa empírica. Rio de Janeiro: Booklink/Fenapef/Necvu, 2010.

26 VARGAS, Joana Domingues. Em Busca da "Verdade Real”: Tortura e confissão no brasil ontem e hoje. Revista Sociologia e Antropologia. Rio de Janeiro, v. 2, n. 3, p. 237-265, jun., 2012. http://dx.doi.org/10.1590/2238-38752012v2310.

27 Aqui, usa-se o termo "prova" em um sentido amplo, a partir das lições de Antonio Magalhães Gomes Filho: "A prova é entendida como "demonstração" quando se diz que ela serve para estabelecer a verdade sobre determinados fatos. Nesta primeira acepção, "provar" significa apresentar elementos de informação idôneos para decidir se a afirmação ou negação de um fato é verdadeira”. GOMES FILHO, Antonio Magalhães. Notas sobre a terminologia da prova: reflexos no processo penal brasileiro. In YARSHELL, Flávio Luiz; MORAES, Maurício Zanoide (org.). Estudos em homenagem à professora Ada Pellegrini Grinover. São Paulo: DPJ, 2005. p. 305. Não obstante, não se nega o entendimento de muitos autores que utilizam o termo "prova" exclusivamente como os elementos que foram submetidos ao crivo do contraditório em fase judicial.

VARGAS, Joana Domingues, op. cit., p. 237-265.

VARGAS, Joana Domingues, op. cit., p. 237-265.

30 "O fenômeno conhecido como primado das hipóteses sobre os fatos foi diagnosticado pelo processualista italiano Franco Cordero. O "inquisidor" somente levará em conta os elementos significantes da hipótese acusatória 
Como bem alertado por Susan Haack, "Se você está tentando encontrar evidências para sustentar uma conclusão precipitada, ao invés de seguir a evidência para onde ela leva, você não está realmente investigando"31. E, em complemento, "quando não é mais o raciocínio que determina qual conclusão que deve ser, mas a conclusão que determina qual raciocínio deve ser, trata-se do raciocínio fingido" ${ }^{32}$.

Dito isso, é imperioso reconhecer que a confissão é primordialmente vista como a revelação da verdade e assume fundamental importância para a formação primária da culpa no contexto brasileiro.

\section{Possíveis Razões PaRa a MAIOR INCIDÊNCIA DE FALSAS CONFISSÕES}

A informalidade presente no ambiente das Delegacias de Polícia, o desrespeito tanto à garantia constitucional do direito ao silêncio e quanto às formalidades inerentes ao interrogatório, além da escassa prestação jurídica oferecida durante o inquérito policial, aparentam ser boas justificativas para uma maior incidência do fenômeno das falsas confissões.

Como ensina Marta Saad, o direito de ser ouvido é consequência direta ao direito de informação, devendo ser considerado como o momento de exercer a sua autodefesa. O acusado/investigado poderá alegar a sua inocência, lançar dúvidas sobre sua culpabilidade, confessar integralmente ou parcialmente os fatos, ou, ainda, manifestar o direito de se manter calado ${ }^{33}$.

$\mathrm{Na}$ prática forense, tanto o direito ao interrogatório quanto ao silêncio são comumente desrespeitados, vez que nem sempre se é alertado

que pretende provar, desprezando os demais. Nessa situação, forma-se um "quadro mental paranóico". CORDERO, Franco. Guida alla procedura penale. Torino: UTET, 1986. p. 51.

31 Tradução livre. HAACK, Susan. Epistemology legalized: Or, Truth, Justice, and the American Way, in Evidence and Inquiry: a pragmatist reconstruction of epistemology. New York: Prometheus Books, 2009. p. 368.

32 HAACK, Susan. Manifesto de uma moderada apaixonada: ensaios contra a moda irracionalista. Trad. Rachel Herdy. Rio de Janeiro: Editora PUC-Rio, 2011. p. 87.

33 SAAD, Marta. O direito de defesa do inquérito Policial. São Paulo: Revista dos Tribunais, 2004. p. 283-284. 
da existência da garantia constitucional ao silêncio ${ }^{34}$. Dificilmente as formalidades previstas no artigo 185 e seguintes do index processual penal são efetivamente seguidas nos interrogatórios policiais. Sem deixar de relembrar a existência das polêmicas "declarações informais" em tese proferidas pelo detido aos policiais, que ao serem ouvidos, relatam que o suspeito teria confessado a prática criminosa, sendo que em muitas situações este conteúdo sequer é ratificado no inquérito policial ou em eventual ação penal ${ }^{35}$.

Ademais, o aconselhamento legal por parte de um advogado antes do interrogatório policial poderia eventualmente desestimular a confissão falsa, na medida em que o indivíduo estaria mais ciente de seus direitos e das consequências que determinada declaração poderia resultar. Isso nem sempre é uma realidade, já que grande parte da população não possui condições financeiras de constituir um advogado particular, encontrando-se, com isso, entregues à própria sorte ${ }^{36}$.

No campo psíquico, é necessário distinguir que nem todas as falsas confissões são provenientes da aplicação de técnicas manipuladoras em interrogatórios, devendo ser levado em conta as características pessoais do suspeito - como é exemplo do tempo de detenção, da idade, da capacidade cognitiva e dos fatores contextuais ${ }^{37}$.

Acerca do caráter temporal, alerta Cristina Di Gesu que a memória humana está sujeita a falhas, uma vez que a lembrança não reconstrói o fato tal qual ocorreu na realidade, sendo mais uma síntese aproximativa daquilo que foi percebido. As recordações, por sua vez, são fortemente influenciadas pela emoção, sendo que quanto maior o transcurso do

34 MOURA, Maria Thereza Rocha de Assis; MORAES, Mauricio Zanoide de. Direito ao silêncio no interrogatório. Revista Brasileira de Ciências Criminais, São Paulo, v. 2, n. 6, p. 133-147., abr./jun., 1994. p. 141.

35 SAAD, Marta, op. cit., p. 293.

36 BARBOSA, André Luis Jardini. A abrangência da garantia constitucional da amplitude de defesa e a sua efetiva aplicação prática durante os plantões policiais. Revista do Curso de Direito da Universidade Federal de Uberlândia, Uberlândia, v. 44, n. 1, p. 34-65, 2016. p. 35.

37 SILVA, Inês Gonçalves Gomes Matos Silva. Falsas confissões e o contexto de investigação: A perspectiva dos investigadores. Dissertação de Mestrado em Psicologia - Instituto Superior de Psicologia Aplicada (ISPA), Lisboa, 2008. p. 11. 
tempo entre os fatos e as primeiras declarações, maior é a possibilidade desse fenômeno também denominado como "falsificação da lembrança"38.

Quanto ao fator idade, Steven Drizen, responsável pelo Center of Wrongful Convictions da Northwestern University School of Law, explica que os jovens são particularmente mais vulneráveis e tendem a ser mais impulsivos, concentrando-se na gratificação a curto prazo. Confessar teria um impacto semelhante ao prêmio de "ir para a casa", a fim de se livrar rapidamente do problema ${ }^{39}$. Os dados estatísticos coletados pelo Innocent Project e National Registry of Exonerations americano - apresentados no início deste artigo - demonstram que a maior incidência de falsas confissões ocorre justamente em pessoas que não são plenamente capazes, seja pelo fator idade ou pela existência de algum distúrbio mental/cognitivo.

Para fins elucidativos, necessário tecer que as falsas confissões são classificadas em três principais categorias ${ }^{40}$. A primeira, conhecida como falsa confissão voluntária, é marcada por uma pressão interna, a partir de motivos particulares que variam de cada indivíduo. Nesta situação, o sujeito confessa voluntariamente, movido por razões que podem ser diversas: É possível que seja acometido de alguma doença emocional, como depressão ${ }^{41}$, que possua uma necessidade consciente ou inconsciente de autopunição, que não saiba muito bem distinguir o que é real ou fantasia, e em último caso, que queira proteger o verdadeiro autor do crime em questão ${ }^{42}$.

A segunda categoria é compreendida pelas falsas confissões involuntárias, que se dividem entre internalizadas e complacentes/coercitivas.

As internalizadas se distinguem principalmente das complacentes em relação à percepção dos fatos, pois o indivíduo não possui a efetiva

38 DI GESU, Cristina Carla. Prova penal e falsas memórias. Dissertação de Mestrado em Ciências Criminais - Faculdade de Direito, Pontifícia Universidade Católica do Rio Grande do Sul, Porto Alegre, 2008. p. 255.

39 INNOCENT PROJECT, op. cit.

40 Trata-se de uma divisão comumente feita entre os pesquisadores. KASSIN, Saul; COLLEGE, Willians. The Psychology of Confession Evidence. American Psychologist, v., 52, n. 3. p. 221-223. 1997. https://doi.org/10.1037/0003-066X.52.3.221.

41 GUDJONSSON, Gisli H. The Psychology of Interrogations and Confessions: A handbook. Chichester: John Wiley \& Sons Ltd, 2003. p. 218.

42 Ibid, p. 218. 
consciência de que não cometeu o delito. Pelo contrário, quem confessa é levado a crer ter sido o autor do crime, ficando suscetível a internalizar opiniões externas e internas ${ }^{43}$, desenvolvendo o fenômeno das falsas memórias do ocorrido ${ }^{44}$. A memória é suscetível à distorção mediante a sugestão de informações posteriores aos eventos, que podem ser tanto acidentais quanto deliberadas ${ }^{45}$. Tais situações são muito comuns em pessoas que fazem o uso constante de entorpecentes e álcool, ou nas situações em que os crimes ocorreram na infância ou juventude ${ }^{46}$, que podem permanentemente se convencer do cometimento de delitos quando na realidade são inocentes, trazendo reflexos de ordem emocional e psicológica irreparáveis.

Ao que interessa ao presente artigo, existem as confissões complacentes/coercitivas. Em geral, elas são consequências de procedimentos externos que se utilizam de técnicas persuasivas em interrogatórios, em que a vulnerabilidade do interrogado é aproveitada. Não é incomum que as pessoas, quando entrevistadas, aceitem mensagens implícitas, e por isso alterem o comportamento e respostas a serem dadas ${ }^{47}$.

43 NEUFELD, Carmem Beatriz; BRUST, Priscila Goergen; STEIN, Lilian Milnistky. Compreendendo o Fenômeno das Falsas Memórias. In: STEIN, Lilian Milnistky. Falsas memórias: Fundamentos científicos e suas aplicações clínicas e jurídicas. Porto Alegre: Artmed, 2010. p. 28.

44 KASSIN, Saul; COLLEGE, Willians, op. cit., p. 226.

45 NEUFELD, Carmem Beatriz; BRUST, Priscila Goergen; STEIN, Lilian Milnistky, op. cit., p. 28.

46 KASSIN, Saul; COLLEGE, Willians, op. cit., p. 226.

47 "A escala de sugestionabilidade de Gudjonsson, GSS1 de 1987, operacionaliza o modelo e proporciona uma medida de recordação auditiva - imediata e deferida - e de sugestionabilidade interrogativa. É constituída por uma história sobre um assalto, apresentada oralmente, por duas tarefas de recordação livre (com um intervalo de 50 minutos) e por um questionário com 20 questões, 15 das quais construídas de modo a induzirem o sujeito ao erro. No final do questionário, o sujeito é informado de que cometeu erros e que, por isto, irá responder novamente às questões, devendo ser mais preciso. Qualquer mudança nas respostas do sujeito do primeiro questionamento para o segundo é considerada uma alteração. Quando o sujeito se deixa influenciar pelas questões que induzem ao erro, considera-se a presença de uma cedência (cedência 1 ou 2), consoante o sujeito cede as questões falaciosas antes ou depois do feedback negativo). A sugestionabilidade total corresponde à adição do total cedência 1, com o total alteração". ÁVILA, Gustavo Noronha de. Falsas Memórias e Sistema Penal: A prova testemunhal em xeque. Rio de Janeiro: Lumen Juris, 2013. p. 117. 
Este fenômeno recebeu a alcunha de "sugestionabilidade interrogativa" 48 .

\section{O MÉTODO REID}

Do que se tem conhecimento, o método foi inicialmente mencionado na primeira versão do manual Interrogation and Confessions de autoria John Reid e Fred Inbau em 1942, sendo a obra republicada com títulos similares e com posteriores contribuições relevantes de Joseph Buckley ${ }^{49}$. John Reid era um investigador de sucesso na polícia, ao passo que Fred Inbau era professor da Northewestern Law School e exercia o cargo de Diretor do laboratório de Detenção de Crimes Científicos da Polícia, ambos em Chicago ${ }^{50}$.

A criação de um método não foi por acaso. Segundo Richard $\mathrm{Leo}^{51}$, havia uma necessidade em se desenvolver uma técnica capaz de identificar a suposta veracidade e confiabilidade das declarações, ainda mais quando a utilização do polígrafo já estava em decadência e com o seu uso restrito pelo governo americano na década de $70^{52}$.

A segunda razão que pode justificar a elaboração de uma nova técnica de interrogatório foi a proibição pela Suprema Corte dos Estados Unidos do "third degree", método que incluía a coerção física e psicológica a partir de longos interrogatórios, privações de sono, água, comida e, por último, agressão física, com a utilização de cigarros para queimar o corpo, choques e uso de elásticos para esconder as marcas da violência ${ }^{53}$.

Em uma comparação elaborada por Richard Leo para tentar ilustrar a importância e a difusão do método na atividade policial:

48 GUDJONSSON, Gisli H.; CLARK, N.K. Suggestibility in police interrogation: a social psychological model. Social Behavior, London, v. 1, p. 195-196, 1986. GUDJONSSON, Gisli H, op. cit., p. 10.

50 REID, John; INBAU, Fred; BUCKLEY, Joseph; JAYNE; Brian. Criminal Interrogations and Confessions. 5 ${ }^{\mathrm{a}}$ ed. Burlington: Jones \& Bartlett Learning, 2004. prefácio (vii).

51 LEO, Richard A, op. cit., p. 7.

52 REID, John; INBAU, Fred; BUCKLEY, Joseph; JAYNE; Brian, op. cit., p. 154.

53 LEO, Richard A. op. cit., p. 8. 
"assim como pode se dizer que praticamente toda literatura moderna é uma variação de Shakespeare, também pode-se dizer que praticamente toda a técnica de interrogatório policial empregada atualmente na América é uma variação do método Reid"54.

Ressalta-se que os próprios Reid, Inbau e Buckley reconhecem que a técnica se estendeu em diversos seminários no Canadá, Europa e Ásia ${ }^{55}$. O sucesso foi tamanho que em 1955, John Reid fundou a John E. Reid \& Associates Inc., sendo atualmente a empresa privada que mais promove treinamentos de interrogatórios no mundo ${ }^{56}$.

Muito embora a dificuldade de se encontrar na doutrina brasileira referências a este tipo de técnica, até mesmo por ser questionável a divulgação das metodologias empregadas pela Academia de Polícia, pode-se afirmar que o método é amplamente ensinado no treinamento de algumas Polícias Civis Estaduais no país. A menção expressa pode ser explicitamente encontrada em manuais utilizados pela Academia de Polícia do Estado da Paraíba ${ }^{57}$, publicações no site da Polícia Civil do Mato Grosso do Sul ${ }^{58}$, ou ainda, mesmo que mais raro, no manual de peças e prática da atividade policial, como o de autoria de Paulo Reyer Camargo Mousinho ${ }^{59}$ e também de Felipe Pereira de Melo, José César de Bittencourt e Luiz Renato Blanchet ${ }^{60}$. Outras Academias de Polícias não fazem alusão expressa

54 Tradução livre. LEO, Richard A, op. cit., 7.

55 REID, John; INBAU, Fred; BUCKLEY, Joseph; JAYNE; Brian, op. cit., prefácio (vii).

56 KOZINSKI, Wyatt, op. cit., p. 303. Além disso, os programas de treinamento da John E. Reid \& Associates Inc. podem ser encontrados em seu site. JOHN REID \&ASSOCIATES INC. Training programs. Disponível em: <https://bit. ly/3585q2w> Acesso em: 08 dez. 2019.

57 COSTA, Cláudio Rodrigues. Técnicas de Entrevista e Interrogatório policial: Curso de Formação de Delegados da Academia de Polícia do Estado da Paraíba. Disponível em: <https://bit.ly/2Rwt9p2> Acesso em: 08 dez 2019.

OLIVEIRA, Wellington de. Aplicando técnicas de entrevista e interrogatório na investigação -método reid. Disponível em: <https://bit.ly/2Ys5Y0q> Acesso em: 06 dez 2019.

59 MOUSINHO, Paulo Reyner Camargo. Peças e prática da atividade policial. $2^{\mathrm{a}}$ Ed. rev., atual e ampl. Macapá: Editora do Autor, 2018. p. 98.

60 MELO, Felipe Pereira de; BLANCHET, Luiz Renato; BITTENCOURT, José Cesar de, op. cit., p. 144. 
ao nome do método Reid, mas revelam características dessa metodologia na descrição das diretrizes de condução do interrogatório ${ }^{61}$. Inclusive, os últimos autores acima mencionados, ao tecerem suas recomendações de qual método entendem ser o mais adequado para o interrogatório, traçam um roteiro muito semelhante ao utilizado por Reid ${ }^{62}$.

Mesmo que os próprios John Reid e Fred Inbau tenham tecido inúmeras críticas ao third degree, chegando até mesmo a mencionar que se trataria de técnica abusiva ${ }^{63}$, pode-se concluir que o método Reid muito pouco se distingue da violência psicológica empregada, sendo apenas uma técnica com roupagem mais sofisticado para incitar a confissão do suspeito, a partir da utilização indiscriminada do blefe e da manipulação psicológica ${ }^{64}$.

De acordo com a metodologia em comento, existem três componentes necessários para eliminar inocentes suspeitos e chegar a uma possível e atingível "verdade", consistente na análise factual, análise do comportamento em entrevista e, ao final, o interrogatório.

Inicialmente, a análise factual se resume em avaliar todos os aspectos do crime e do possível criminoso, sendo realizadas inferências

61 Dentre elas, estão a Academia de Polícia de Minas Gerais, Academia de Polícia de Pernambuco e Academia de Polícia de São Paulo. MARQUES, Leonardo Augusto Marinho; SARKIS, Jamilla Monteiro. Interrogatório policial, confissões forçadas e hipóteses de culpa. Revista Brasileira de Ciências Criminais, São Paulo, v. 27, n. 156, p. 249-278, jun., 2019. p. 259.

62 Segundo Felipe Pereira de Melo, José César de Bittencourt e Luiz Renato Blanchet, o roteiro básico de interrogatório deverá resumidamente seguir os seguintes passos: (i) sempre se deve fazer uma acusação firme e incisiva, baseada na convicção do interrogador, que não poderá ser desfeita; (ii) o interrogador deve oferecer atrativos para que a pessoa confesse, seja pelo redirecionamento da culpa, redução da magnitude do fato ou proporcionando a má e a boa opção; (iii) deverão ser impedidas as negativas dos interrogados, as quais necessitam ser estritamente controladas pelo interrogador; (iv) deverão ser impedidos os protestos do interrogado; (iv) e por fim o interrogador deverá adotar condutas que evitem o desligamento (retomar a atenção do interrogado). MELO, Felipe Pereira de; BLANCHET, Luiz Renato; BITTENCOURT, José Cesar de, op. cit., p. 131/137. dor. Dissertação de mestrado em cognição humana - Faculdade de Psicologia da Pontifícia Católica do Rio Grande do Sul, Porto Alegre, 2010. p. 33. 
dedutivas a fim de localizar possíveis autores ${ }^{65}$. Já a análise comportamental (The Behavior Analysis Interview - BAI) consiste na realização de entrevistas de estrutura não acusatórias, que duram cerca de 30 a 40 minutos, com roteiro livre e com a finalidade de elucidar alguns pontos investigativos e informações comportamentais ${ }^{66}$.

O investigador passa a realizar questionamentos sobre endereço, estado civil, profissão e outros dados pessoais, que supostamente possibilitariam ao entrevistador a avaliação do comportamento verbal e não verbal do entrevistado, como a reticência ao responder as perguntas e o contato visual.

Após o estabelecimento de premissas sobre o suposto comportamento do entrevistado, são realizadas perguntas provocadoras (behavior-provoking questions), projetadas para extrair respostas verbais e não verbais que supostamente seriam capazes de diferenciar os verdadeiros suspeitos dos inocentes, além de, em tese, facilitar a formulação de uma estratégia a ser aplicada no interrogatório de suspeitos "culpados"67.

O interrogatório, por sua vez, é pautado por diversos questionamentos assertivos, em que já se presume de imediato a culpa do inquirido. Através da persuasão e pressão, em que o monólogo é valorizado para desencorajar o suspeito a falar até o momento que estiver considerado como pronto para dizer a suposta "verdade", o investigador induz o sujeito a parar de negar a hipótese inicialmente mencionada, para que assim passe a admitir a prática delitiva ${ }^{68}$.

Tais táticas estão contempladas pela mescla de ações de "maximização" e "minimização" por parte dos interrogadores, expressão cunhadas por Saul Kassin e Karin McNall ${ }^{69}$, consistentes na utilização simultânea de condutas como a intimidação e blefe, com toques de aproximação, simpatia e preocupação com o entrevistado. Essa fusão

65 JOHN REID \& ASSOCIATES INC. Critics Corner - The reid technique. Disponível em: <https://bit.ly/36jrc39> Acesso em: 08 dez. 2019.

REID, John; INBAU, Fred; BUCKLEY, Joseph; JAYNE; Brian, op. cit., p. 154.

JOHN REID \& ASSOCIATES INC, op. cit.

68 LEO, Richard A, op. cit., p. 9.

69 KASSIN, Saul; MCNALL, Karin. Police interrogations and confessions: Communicating promises and threats by pragmatic implication. Law and $\mathrm{Hu}-$ man Behavior. v. 15, p. 233-251, 1991. 
seria um dos principais motivos pelos quais a técnica foi considerada tão promissora na extração de admissões.

\section{O PASSO A PASSO DA TÉCNICA INTERROgATIVA REID}

Para a obtenção de uma confissão, são descritos nove passos a serem seguidos: 1) confrontação direta, 2) introdução e desenvolvimento do tema de interrogatório, 3) a reversão das negações, 4) a reversão das objeções, 5) a busca pela retenção da atenção, 6) o reconhecimento da resignação, 7) a apresentação da questão alternativa, 8) a obtenção da confissão oral e, por fim, a 9) conversão para a confissão escrita.

Resumidamente, no primeiro passo, são apresentados os principais fatos do caso e dito categoricamente ao suspeito que existem provas contra ele e que o crime já está praticamente solucionado ${ }^{70}$. Nesse momento, sugere-se ao interrogador que seja direto ao ponto e esteja seguro ${ }^{71}$, mesmo que esteja blefando ou mentindo, já que é necessário analisar o comportamento do interrogado ao reagir sobre o questionamento. Um exemplo de indagação a ser feita é a seguinte: "Andy, eu tenho os resultados sobre a investigação do desaparecimento de R 3000 mil reais da loja que ocorreu neste último sábado. Os resultados indicam que foi você que pegou o dinheiro"72. Segundo o manual da técnica, se o suspeito virar o olho, mudar sua postura na cadeira ou der respostas muito vagas, é provável que esteja mentin$\mathrm{do}^{73}$. Do contrário, se estiver focado e mantiver contato direto com o investigador, aparentando estar em choque ou com raiva, é provável que seja inocente.

No segundo passo, recomenda-se a introdução do tema. Ao interrogador caberá desenvolver sua hipótese do ocorrido e trazer ao

70 MOUSINHO, Paulo Reyner Camargo, op. cit., p. 98.

71 MELO, Felipe Pereira de; BLANCHET, Luiz Renato; BITTENCOURT, José Cesar de, op. cit., p. 145.

72 JOHN REID \&ASSOCIATES INC, op. cit.

73 Ibid. O passo a passo do método está simplificado pela própria John \& Reid Associates e foi em sua maioria resumido a partir das informações constantes no site. 
interrogado boas razões para o cometimento do delito, como uma forma de minimizar a responsabilidade por essa ação e diminuir a sensação de culpa ${ }^{74}$. A narrativa deve ser feita de forma tranquila e suave. Com pessoas mais sensíveis poderá ser feita uma aproximação empática, ao passo que, para os mais racionais, é imprescindível uma abordagem mais pragmática ${ }^{75}$.

Em seguida, deverá ser iniciada a etapa da reversão das negações. O método parte do pressuposto de que dificilmente o suspeito confessará imediatamente a prática do crime, razão pela qual passará a negar os fatos.

Caberá ao interrogador impedir o interrogado que apresente suas negativas. Argumentos como "Aqui não há nenhuma dúvida sobre isso. O que eu gostaria de fazer agora é sentar com você para ver se podemos resolver isso. Veja, Andy, em situações como essa, é importante entender as circunstâncias que o levaram a cometer esse tipo de coisa"76. Se o interrogado tentar apresentar alguma desculpa, o interrogador deverá interromper e desenvolver o tema, podendo se utilizar de frases como: "Andy, o modo como a economia de hoje está destruindo tantas vidas com preços inflacionados e desemprego, vemos pessoas como você cometendo erros assim o tempo todo" 77 , "você já teve o seu tempo de falar, agora é o meu"78.

Já no quarto estágio, é possível que o suspeito possa contrapor questões de natureza lógica e não meramente negativas, como "Eu nunca poderia ter roubado alguém, pois minha casa foi assaltada quando eu era criança"79. Essas objeções, em tese, indicariam que o investigador está fazendo um progresso substancial, sendo que ele deverá fingir aceitá-las como verdadeiras, para então usá-las a seu favor no desenvolvimento

74 MELO, Felipe Pereira de; BLANCHET, Luiz Renato; BITTENCOURT, José Cesar de, op. cit., p. 146.

75 MARQUES, Leonardo Augusto Marinho; SARKIS, Jamilla Monteiro. op. cit., p. 250 .

76 JOHN REID \&ASSOCIATES INC, op. cit.

77 Ibid.

78 MELO, Felipe Pereira de; BLANCHET, Luiz Renato; BITTENCOURT, op. cit., p. 146.

79 JOHN REID \&ASSOCIATES INC, op. cit. 
posterior do tema, por exemplo "Andy, eu sei desta situação horrível e sei que você apenas cometeu este erro. Ninguém imaginava que você iria ficar tão sem dinheiro assim"80, ou ainda, "você é bom, mas agiu por impulso"81.

No quinto passo, é bem provável que o interrogado já esteja permeado por uma sensação de frustração e insegurança sobre a dinâmica dos fatos e sobre si mesmo. De acordo com o método, uma pessoa inocente não passará do passo três (a reversão das negações), pois continuará negando os fatos, enquanto os verdadeiros "culpados" ficarão quietos, pensativos e reclusos. Nessa última hipótese, o interrogador tem a missão de agir para fixar a atenção do interrogado, a partir da diminuição da distância física entre eles, criando uma zona pessoal, ou também o emprego de contato visual e de perguntas retóricas ${ }^{82}$.

Em seguida, na sexta etapa, deverá o investigador reconhecer a resignação do interrogado e aproveitar-se de sua vulnerabilidade, já que os cinco primeiros passos são marcados por uma postura ativa do entrevistador, enquanto este representa um convite para que o interrogado passe a se expressar.

De acordo com Reid, o suspeito culpado terá percebido a ineficácia de seus esforços para frustrar o investigador, e assim entender a necessidade de falar a verdade, sendo muito comum choros indicando "remorso" do suspeito, ou, ainda, cabeça e ombros caídos, pernas relaxadas e olhares vagos.

Se o interrogado estiver chorando, podem ser ditas frases como: "Eu sei o quanto você tentou manter isso dentro, mas estou feliz em ver essas lágrimas porque elas me dizem que você está arrependido por isso ter acontecido - você está arrependido por ter feito isso, não é?"83.

A partir disso, o interrogador deverá ter uma postura compreensiva para estimulá-lo e induzi-lo a confessar a prática do crime a partir

80 Ibid.

81 MELO, Felipe Pereira de; BLANCHET, Luiz Renato; BITTENCOURT, José Cesar de, op. cit., p.147.

82 MARQUES, Leonardo Augusto Marinho; SARKIS, Jamilla Monteiro, op. cit., p. 261.

83 JOHN REID \&ASSOCIATES INC, op. cit. 
de uma das hipóteses postas, sendo que, em geral um dos cenários terá maior grau de exculpação e o outro, mais repreensível. Podem ser usadas frases de acolhimento como: "Andy, eu tenho certeza que você tinha muitas contas para pagar e cuidar, motivo pelo qual roubar o dinheiro poderia resolver todos os seus problemas", ou ainda, "Você na realidade não tinha outra saída para essa terrível situação" ${ }^{84}$.

O sétimo passo, por sua vez, consiste em oferecer alternativas, estimulando o interrogado para que dê mais detalhes do delito, criando opções boas e ruins ${ }^{85}$ até que o suspeito demonstre com mais detalhes que escolherá uma delas. Os componentes podem contrastar com uma ação desejável e outra indesejável, como "É a primeira vez que algo assim acontece ou você já fez esse tipo de coisa centenas de vezes antes?" "Acho que é a primeira vez, não é?" 66 . A escolha da opção primeira vez pelo investigado reflete a necessidade de um desenvolvimento do tema, diverso do que seria feito em relação à segunda.

A confissão, objetivo principal a ser atingido (passo oito), começa a partir do momento em que o interrogado demonstra que escolheu uma das alternativas narradas pelo interrogador. Se da questão anterior ele confirmar assertivamente, recomenda-se ao investigador que realize uma declaração de reforço, a fim de confirmar a admissão da culpa oral, como por exemplo "foi o que eu pensei o tempo todo" ${ }^{87}$.

Ao final, recomenda-se que a confissão seja reduzida a um documento escrito ${ }^{88}$, brevemente e da forma mais completa, pois é possível que o interrogado mude de ideia e consequentemente queira se retratar, sendo esta a última etapa do método Reid (passo nove).

84 Ibid.

85 MELO, Felipe Pereira de; BLANCHET, Luiz Renato; BITTENCOURT, op. cit., p. 147.

86 JOHN REID \&ASSOCIATES INC., op. cit.

87 Ibid.

88 MELO, Felipe Pereira de; BLANCHET, Luiz Renato; BITTENCOURT, José Cesar de, op. cit., p. 148. 


\section{Críticas ao método Reid e possíveis alternativas à METODOLOGIA}

Feitas as considerações detalhadas sobre o procedimento ensinado por John Reid e a sua utilização nas investigações criminais, é evidente que este método possui traços característicos de natureza inquisitorial. Pressões psicológicas, blefes, falsas promessas, constrangimento emocional, consistem em alguns dos instrumentos são utilizados em prol do prêmio final, que é a confissão.

Justamente por conta de seu caráter instrumentista, alguns manuais policiais brasileiros chegam até mesmo advertir que "a implementação exaustiva (do método Reid) pode levar pessoas inocentes a confessar algo que não fizeram simplesmente para fugir do estresse causado pela situação" ${ }^{\text {89 }}$. E por isso, para estes autores, seria preferível a sua utilização apenas quando constatados bons indícios relativos à autoria ${ }^{90}$.

Essa situação desnatura diretamente a finalidade da investigação sob a perspectiva epistemológica, em que seu objeto seria uma possível tentativa de reconstituição fática aproximativa da verdade, como uma correspondência da hipótese com o mundo ${ }^{91}$. Se entendermos que a verdade ${ }^{92}$ sempre deverá, mesmo que de forma utópica, consistir em um dos principais objetivos que norteiam o procedimento, ainda

89 Ibid, p. 148.

90

Ibid, p. 148.

91 "A verdade de uma afirmação consiste em sua adequação à realidade (ou estado das coisas) a que se refere, em sua correspondência com os fatos". Tradução livre. GASCÓN ABELLAN, Marina, op. cit., p. 115.

92 Em que pese as inúmeras discussões filosóficas e vertentes sobre o conceito de verdade, entende-se que o tratamento dela como "correspondência" parece ser o modelo mais adequado para lidar com a questão probatória dentro da investigação e do procedimento judicial. Merece destaque o ensinamento de Jordi Ferrer Beltran, que ao afirmar que "p está provado”, não significa que "p é verdadeiro", devendo ser entendido como "existem elementos de prova suficientes a favor de p”. Ainda, uma preposição que esteja provada, não necessariamente é verdadeira, pois uma hipótese fática pode resultar provada, ainda que seja em sua essência falsa. Tal conceituação possibilita a reversão de erros judiciais a partir da utilização de revisão criminal. FERRER BELTRAN, Jordi. Prueba y verdad en el derecho. $2^{\text {a }}$ Ed. Madri: Marcial Pons, 2005. p. 35. 
que não seja o único fim que o processo persegue ${ }^{93}$, é imprescindível discutir que a correta reconstituição dos fatos, especialmente realizada em sede de investigação criminal, é elemento essencial para uma decisão mais justa.

Imprescindível rememorar as lições de Geraldo Prado, que define que a delicada situação de uma investigação - não controlável racionalmente - pode conduzir, em seu extremo, a prática de exercícios retóricos de desvaloração, quando ela na realidade ocupa um lugar essencial e central em hipotética decisão condenatória94. E na prática, é justamente o que vemos: O procedimento que busca apurar as circunstâncias, autoria e materialidade do delito focado quase que exclusivamente no investigado como principal fonte de provas, torna-se um procedimento descredibilizado em que, em certas ocasiões, duvidamos em maior grau justamente daqueles que conduziram toda a atividade investigativa.

Admitir que a confissão possui um papel fundamental em detrimento dos outros elementos de informação e extraí-la a partir da manipulação psicológica, é reconhecer a existência de certa preguiça dos responsáveis pela a averiguação, ocorrendo o fenômeno denominado "anclaje" 95 nas primeiras impressões. Ou melhor, o investigador fixa as crenças das primeiras observações e conjecturas realizadas,

93 TARUFFO, Michele. Uma simples verdade: o juiz e a construção dos fatos. Trad. de Vitor de Paula Ramos. São Paulo, Marcial Pons, 2012. p. 160.

94 PRADO, Geraldo Luiz Mascarenhas. Prova penal e sistema de controles epistêmicos: a quebra da cadeia de custódia das provas obtidas por métodos ocultos. São Paulo: Marcial Pons, 2014. p. 56.

95 Para exemplificar essa falibilidade dos outros métodos, Pablo Bonorino menciona o exemplo lecionado por Mario Bunge, citando uma hipótese em que uma vizinha vê uma jovem chegar em casa, acompanhada de um homem diferente de seu namorado. A primeira hipótese conjeturada pela vizinha é a de que a jovem teria traído seu companheiro, mantendo-a com o passar do tempo, reafirmando que "viu com seus próprios olhos". Este "anclaje”, por exemplo, impediu que esta verificasse outras hipóteses, quais sejam, que o homem fosse irmão da jovem, ou conectar a visita recebida com o incêndio que havia destruído o centro da cidade em que se viviam. BONORINO, Pablo Raúl. Ni deduccion ni inducción: abducción. In: GARCIA AMADO, Juan Antonio; BONORINO, Pablo Raúl (org.). In: Prueba y razonamiento probatório em el derecho: debates sobre abducción. Granada: Comares, 2014. p. 176. 
renegando as demais que poderiam ser abordadas para explicar os mesmos fatos.

Uma investigação efetivamente qualificada deveria, por sua vez, afastar a confissão como principal meio de prova e seguir o método abdutivo como principal atividade inferencial ${ }^{96}$ desenvolvido por Charles Peirce. Este raciocínio é considerado como processo pelo qual brotam, engendram-se, algumas hipóteses ou conjecturas, diante de um fato surpreendente, partindo de uma análise inversa: dos fatos às explicações, das conclusões às premissas, e no caso da atividade investigativa, do presente ao passado ${ }^{97}$. Ela é entendida como a única operação lógica capaz de introduzir uma ideia nova ${ }^{98}$.

A metodologia segue as seguintes etapas:

(i) Observação dos dados disponíveis;

(ii) Formulação de um problema;

(iii) Criação de hipóteses que resolvem o problema;

(iv) Busca de nova informação;

(v) Confirmação ou refutação das hipóteses com a possível resposta;

(vi) Repetição dos passos (i) a (iii);

(vii) Busca de nova informação;

(viii) Confirmação ou refutação da nova hipótese ou resposta;

(ix) Repetição dos passos (vi) a (viii) tantas vezes que forem necessárias;

(x) Aceitação de uma das hipóteses ou respostas como provável.

96 As inferências, como apontam Janaina Matida e Rachel Herdy, compõem-se de três elementos: a hipótese fática sugerida para dar conta de certos fatos ou eventos; as informações ou meio de prova que dão suporte a tal hipótese e a ligação entre esses elementos. MATIDA, Janaina; HERDY, Rachel. As inferências probatórias: compromissos epistêmicos, normativos e interpretativos. In: CUNHA, José Ricardo (org). Epistemologia: Críticas do Direito. Rio de Janeiro: Lumen Juris, 2016. p. 219-232. 
É importante reconhecer que qualquer procedimento judicial está sujeito a erros, na medida em que ele decorre da análise humana acerca de fatos pretéritos. Por isso mesmo, a criação de um modelo processual crítico, preocupado especialmente na identificação, distribuição e diminuição de erros ${ }^{99}$, é instrumento essencial para uma decisão mais justa ${ }^{100}$. "O processo penal deve ser conduzido para que de tal maneira, quando algum erro ocorra, este seja com maior probabilidade de uma absolvição falsa e não uma condenação falsa" ${ }^{101}$.

Esta metodologia viabiliza a hipótese de lidar com a existência de equívocos quanto à reconstrução fática imaginada. Muitas vezes as conjecturas iniciais não se confirmam com novas informações. Desta feita, o investigador com "integridade intelectual" ${ }^{102}$, embora inicialmente esteja comprometido com sua hipótese preliminar, poderá abandoná-la nas circunstâncias que seus experimentos falsearem a hipótese originária ${ }^{103}$, razão pela qual se entende que somente a abdução é apta a proporcionar a descoberta de fatos inéditos.

Após serem descartadas diversas hipóteses e estabelecida aquela com maior probabilidade de ocorrência, através da inferência probatória abdutiva, uma opção mais adequada à prática interrogativa seria a aplicação do aporte científico proveniente da psicologia do testemunho.

99 Tradução livre. LAUDAN, Larry, op. cit., p. 22.

${ }^{100}$ No tocante aos reflexos na ação penal, como bem preconizou Michele Taruffo e complementou Gustavo Badaró, para que uma decisão seja justa, ela deverá está condicionada por um trinômio, consistente em: (i) um correto juízo do fato, que tenha como finalidade uma correta reconstrução dos fatos; (ii) uma correta interpretação das regras jurídicas, em especial quanto às atividades de hermenêutica e aplicação da lei penal; e por fim, (iii) o emprego de um procedimento válido, com o respeito às garantias, aos direitos e ao devido processo legal. TARUFFO, Michele. Idee per uma teoria dela decisione giusta. Rivista trimestrale di diritto e procedura civile, Milano, p. 315-328, 1997. apud BADARÓ, Gustavo. op. cit., p. 19.

${ }^{101}$ LAUDAN, Larry. op. cit., p. 22.

${ }^{102}$ Expressão cunhada por Susan Haack. Tradução livre: “É obrigação do investigador procurar todas as provas que puder e as avaliar com a máxima imparcialidade". E completa: "um investigador isento e desinteressado é uma espécie de pleonasmo, e um investigador isento e interessado é um oximoro". HAACK, Susan, 2009, op. cit., p. 30.

${ }^{103}$ BADARÓ, Gustavo, op. cit., p. 147. 
Relevante são as contribuições trazidas pelo método PEACE (preparation and planning, engage and explain, acount, closure e evaluate), técnica investigativa originária no Reino Unido em meados de 1990 e desenvolvida a partir da entrevista cognitiva ${ }^{104}$. Criada com o objetivo de garantir maior proteção dos entrevistados em relação às técnicas historicamente aplicadas pelos detetives e policiais ${ }^{105}$, ela já é amplamente utilizada na Austrália, Nova Zelândia e Noruega ${ }^{106}$. Países como o Vietnam, Indonésia, Hong Kong, Malásia e Irlanda, por sua vez, ainda estão adotando progressivamente as suas características.

Sinteticamente, são 05 fases a serem seguidas durante a entrevista investigativa:

(i) preparação e planejamento: deverá ser criado um plano escrito do interrogatório com planejamento e preparo, em que o entrevistador deverá se assegurar que todas as questões fundamentais serão abordadas durante a entrevista ${ }^{107}$. As perguntas e o espaço físico deverão ser previamente organizados.

(ii) engajamento e explicação: através de uma escuta ativa, com uma relação harmoniosa, empática e de conexão ${ }^{108}$, interrogador deverá explicar as sistemáticas, os objetivos da entrevista e administrar o processo com cautela, esclarecendo pontos de dúvida e encorajando o entrevistado a cooperar a dizer a verdade ${ }^{109}$.

${ }^{104} \mathrm{O}$ modelo de entrevista cognitiva foi idealizado em 1984 pelos psicólogos americanos Ronald P. Fisher e Edward Gieselman. Em linhas gerais, o principal fundamento consiste em estruturar a entrevista para ser mais compatível com a atividade cerebral e com a forma que ele recupera memórias. AMBROSIO, Graziella. Psicologia do testemunho: técnicas de entrevista cognitiva. Revista LTR, São Paulo, v. 78, n. 11, p. 31-51, 2014.

105 MELO, Felipe Pereira de; BLANCHET, Luiz Renato; BITTENCOURT, José Cesar de, op. cit., p. 116.

106 SCHOLLUM, Mary. Bringing PEACE to United States: A Framework for investigative interview. Police Chief Magazine, p. 30-37, 2017.

107 GUDJONSSON, Gisli H., op. cit., p. 53.

108 BALLARDIN, Maria da Graça, op. cit., p. 53.

${ }^{109}$ MELO, Felipe Pereira de; BLANCHET, Luiz Renato; BITTENCOURT, José Cesar de, op. cit., p. 117. 
(iii) relato e clarificação: a terceira etapa basicamente consiste no relato do entrevistado, em que o interrogador permite que ele discorra livremente sobre o assunto. São criados alguns estímulos para que o entrevistado volte a se recordar de todas as informações, a fim de maximizar a quantidade e qualidade das informações recordadas ${ }^{110}$.

(iv) fechamento do interrogatório: assim que for finalizado o interrogatório, deverão ser resumidos os principais pontos da entrevista e oportunizado ao interrogado corrigir ou adicionar qualquer informação, havendo a possibilidade de esclarecer os pontos controversos. Também é estimulado que o entrevistador deixe o entrevistado em um estado emocional positivo, tendo em vista a cooperação que foi realizada ${ }^{111}$.

(v) avaliação: ao final, o processo não é finalizado quando o entrevistador se despede do investigado ${ }^{112}$. Deverá ser analisado todo o conteúdo da entrevista, em confronto com os demais elementos colhidos durante a investigação.

Não se pretende no presente artigo se aprofundar suas particularidades da técnica PEACE, mas ela pode ser compreendida como uma ruptura significativa na mentalidade inquisitória tradicional ${ }^{113}$. Nas palavras de Derek Morgan e Geoffrey Stephenson, “O propósito principal da entrevista deixa, então, de ser a obtenção de uma confissão e passa a ser a busca de informações de qualidade, a fim de se determinar a verdade" ${ }^{114}$. Os interrogadores são proibidos blefarem e ao interrogado é permitido

\footnotetext{
${ }^{110}$ AMBROSIO, Graziella, op. cit.

111 Ibid.

${ }^{112}$ STEIN, Lilian; PERGHER, Giovanni Kuckartz; FEIX, Leandro da Fonte. Desafios da oitiva de crianças e adolescentes: técnica de entrevista investigativa. Programa Nacional de Enfrentamento da Violência Sexual Contra Crianças e Adolescentes. Disponível em: < https://bit.ly/32Mk3be>. Acesso em: 03/03/2020.

113 BALLARDIN, Maria da Graça, op. cit., p. 28.

${ }^{114}$ MORGAN, D; STEPHENSON, G. Suspicion and Silence: The Right to Silence in Criminal Investigations. London: Blackstone Press, 1994. p. 165.
} 
que ele possa discorrer livremente sobre o tema, o que em tese resultaria em uma menor incidência de prejulgamentos errôneos sobre a culpa ou inocência de determinado investigado ${ }^{115}$.

Em suma, tanto o método abdutivo como atividade inferencial investigativa, tanto como a metodologia PEACE como forma de entrevista podem ser alternativas interessantes à aplicação do método Reid.

\section{Considerações Finais}

O presente artigo buscou realizar uma introdução ao leitor sobre o método Reid de interrogatório e sua possibilidade de induzir falsas confissões, a partir do caso americano mais conhecido sobre a temática.

Buscou-se analisar a herança trazida pelo sistema processual inquisitório. Como mencionado, a confissão ainda ocupa um lugar central na versão apresentada pelo acusador, ainda que nosso sistema penal seja entendido como acusatório, após a Constituição de 1988 e com as novas reformas estabelecidas pela Lei $\mathrm{n}^{\circ} 13.964 / 2019$. No sistema brasileiro, a confissão ainda é prestigiada ao patamar de rainha das provas, sendo fundamental para a formação da culpa do investigado, a ser auferida pela Autoridade Policial.

Em seguida, foram expostos alguns dos principais motivos pelos quais as pessoas confessam falsamente, sendo encontradas explicações provenientes do campo do direito e da psicologia. Evidenciou-se, sobretudo, que os mais jovens e aqueles com algum distúrbio metal ou psicológico estão mais suscetíveis a essa prática, em especial por conta da atuação dos entrevistadores em sede policial, que muitas vezes realizam a sugestionabilidade interrogativa.

Também se concluiu que a metodologia Reid, que veio a surgir como uma alternativa ao third degree, ainda perpetua a violência dos inquisidores, na medida em que este método, ainda que mais sofisticado, visa incitar a confissão do suspeito com a utilização do blefe e da manipulação

115 SCHOLLUM, Mary, op. cit. 
psicológica ${ }^{116}$. E a considerável quantidade de referências sobre o método no Brasil, por sua vez, demonstram inegavelmente a permanência do caráter inquisitório e coercitivo adotado pela polícia judiciária.

Ao final, foram apresentadas soluções viáveis provenientes da inferência probatória abdutiva - como forma de levantamento de hipóteses - e a utilização do método de entrevista PEACE. Ambos podem ser considerados instrumentos aliados à melhora qualitativa dos interrogatórios e das técnicas empregadas em entrevistas policiais.

Vale dizer, no entanto, que enquanto a mentalidade policialesca permanecer sendo difundida nas investigações criminais, é certo que estar-se-á longe de ter uma apuração qualificada ou que respeite as garantais processuais do investigado, tendo em vista que este, pela leitura legal sistêmica, deveria ser considerado como um sujeito de direitos e não como mera fonte de provas.

O que pode ser considerado por alguns uma vitória na resolução de um caso, é o escancaro da incapacidade e mediocridade dos métodos investigativos, pois a verdade do "torturado" não é a suposta verdade a ser atingida, mas aquela imposta e produzida pelo seu inquisidor ${ }^{117}$.

\section{REFERÊNCIAS}

AMBROSIO, Graziella. Psicologia do testemunho: técnicas de entrevista cognitiva. Revista LTR, São Paulo, v. 78, n. 11, p. 31-51, 2014.

ÁVILA, Gustavo Noronha de. Falsas Memórias e Sistema Penal: A prova testemunhal em xeque. Rio de Janeiro: Lumen Juris, 2013.

BADARÓ, Gustavo Henrique Ivahy. Epistemologia judiciária e prova penal. São Paulo: Thompson Reuters Brasil, 2019.

BALLARDIN, Maria da Graça. A entrevista Investigativa e o policial entrevistador. Dissertação de Mestrado em cognição humana - Faculdade de Psicologia da Pontifícia Católica do Rio Grande do Sul, Porto Alegre, 2010.

116 BALLARDIN, Maria da Graça, op. cit., p. 33.

117 COUTINHO, Jacinto Nelson de Miranda, op. cit., p. 29. 
BARBOSA, André Luis Jardini. A abrangência da garantia constitucional da amplitude de defesa e a sua efetiva aplicação prática durante os plantões policiais. Revista do Curso de Direito da Universidade Federal de Uberlândia, Uberlândia, v. 44, n. 1, p. 34-65, 2016.

BONORINO, Pablo Raúl. Ni deduccion ni inducción: abducción. In: GARCIA AMADO, Juan Antonio; BONORINO, Pablo Raúl (org.). Prueba y razonamiento probatório em el derecho: debates sobre abducción. Granada: Comares, 2014.

COSTA, Cláudio Rodrigues. Técnicas de Entrevista e Interrogatório policial: Curso de Formação de Delegados da Academia de Polícia do Estado da Paraíba. Disponível em: <https://bit.ly/2Rwt9p2> Acesso em: 08 dez. 2019.

CORDERO, Franco. Guida alla procedura penale. Torino: UTET, 1986.

COUTINHO, Jacinto Nelson de Miranda. O papel do novo juiz no processo penal. COUTINHO, Jacinto Nelson de Miranda (org.). In: Crítica à teoria geral do direito processual penal. Rio de Janeiro: Renovar, 2001.

DI GESU, Cristina Carla. Prova penal e falsas memórias. Dissertação de Mestrado em Ciências Criminais - Faculdade de Direito, Pontifícia Universidade Católica do Rio Grande do Sul, Porto Alegre, 2008.

EYMERICH, Nicolau. Manual dos inquisidores. Rio de Janeiro: Rosa dos tempos, 1993.

FERRER BELTRAN, Jordi. Prueba y verdad en el derecho. $2^{\text {a }}$ Ed. Madri: Marcial Pons, 2005.

GAVIN, Helen. Criminological and Forensic Psychology. Londres: Sage Publications Ltd., 2014.

GASCÓN ABELLAN, Marina. Los hechos en el derecho: bases argumentales de la prueba. 3a ed. Madri: Marcial Pons, 2010.

GÉNOVA, Gonzalo. Charles S. Peirce: la lógica del descubrimiento. Navarra: Universidad de Navarra, 1996.

GRINOVER, Ada Pellegrini. Influência do Código de Processo Penal para Ibero -América na legislação latino-americana. Revista Brasileira de Ciências Criminais, São Paulo, v. 1, p. 542-574, 1993. 
GOMES FILHO, Antonio Magalhães. Notas sobre a terminologia da prova: reflexos no processo penal brasileiro. In YARSHELL, Flávio Luiz; MORAES, Maurício Zanoide (org.). Estudos em homenagem à professora Ada Pellegrini Grinover. São Paulo: DPJ, 2005.

GUDJONSSON, Gisli H.; CLARK, N.K. Suggestibility in police interrogation: a social psychological model. Social Behavior, London, v. 1, p. 195-196, 1986.

GUDJONSSON, Gisli H. The Psychology of Interrogations and Confessions: A handbook. Chichester: John Wiley \& Sons Ltd, 2003.

HAACK, Susan. Epistemology legalized: Or, Truth, Justice, and the American Way, in Evidence and Inquiry: a pragmatist reconstruction of epistemology. New York: Prometheus Books, 2009.

HAACK, Susan. Manifesto de uma moderada apaixonada: ensaios contra a moda irracionalista. Trad. Rachel Herdy. Rio de Janeiro: Editora PUC-Rio, 2011.

JOHNSON, Matthew. The Central Park Jogger Case-Police Coercion and Secrecy in Interrogation. Journal of Ethnicity in Criminal Justice, v. 3, p. 131-143, 2005. https://doi.org/10.1300/J222v03n01_07.

KASSIN, Saul; MCNALL, Karin. Police interrogations and confessions: Communicating promises and threats by pragmatic implication. Law and Human Behavior. v. 15, p. 233-251, 1991. https://doi.org/10.1007/BF01061711.

KASSIN, Saul; COLLEGE, Willians. The Psychology of Confession Evidence. American Psychologist, v. 52, n. 3, p. 221-223, 1997. https://doi. org/10.1037/0003-066X.52.3.221.

KHALED JR, Salah H. A busca da verdade no processo penal: para além da ambição

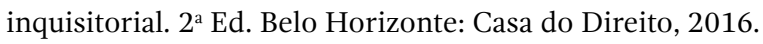

KOEN, Wendy. Case Study: The Central Park five. In: KOEN, Wendy; BOWERS, C. Michael. The Psychology and Sociology of Wrongful Convictions. Academic Press. Londres, 2018. p. 332.

KOZINSKI, Wyatt. The Reid Interrogation Technique and False Confessions: A Time for Change. Seattle Journal for Social Justice, Forthcoming. 2017.

LAUDAN, Larry. Verdad, error y processo penal. Um ensayo sobre epistemologia jurídica. Trad. Carmen Vázquez y Edgar Aguilera. Madri: Marcial Pons, 2013. 
LEO, Richard A. Police interrogation and suspect confessions: social science, law and public policy. Academy of Justice: a report on scholarship and criminal justice reform, Cambridge, v. 6, 2017. https://doi.org/10.1017/9781108354721.010.

MARQUES, Leonardo Augusto Marinho; SARKIS, Jamilla Monteiro. Interrogatório policial, confissões forçadas e hipóteses de culpa. Revista Brasileira de Ciências Criminais, São Paulo, v. 27, n. 156, p. 249-278, jun., 2019.

MATIDA, Janaina; HERDY, Rachel. As inferências probatórias: compromissos epistêmicos, normativos e interpretativos. In: CUNHA, José Ricardo (org). Epistemologia: Críticas do Direito. Rio de Janeiro: Lumen Juris, 2016.

MELO, Felipe Pereira de; BLANCHET, Luiz Renato; BITTENCOURT, José Cesar de. Técnicas de Entrevista e interrogatório. Curitiba: Intersaberes, 2019.

MISSE, Michel. O inquérito policial no Brasil: uma pesquisa empírica. Rio de Janeiro: Booklink/Fenapef/Necvu, 2010.

MORGAN, D; STEPHENSON, G. Suspicion and Silence: The Right to Silence in Criminal Investigations. London: Blackstone Press, 1994.

MOURA, Maria Thereza Rocha de Assis; MORAES, Mauricio Zanoide de. Direito ao silêncio no interrogatório. Revista Brasileira de Ciências Criminais, São Paulo, v. 2, n. 6, p. 133-147, abr./jun. 1994.

MOUSINHO, Paulo Reyner Camargo. Peças e prática da atividade policial. $2^{\text {a }}$ Ed. rev., atual e ampl. Macapá: Editora do Autor, 2018.

NEUFELD, Carmem Beatriz; BRUST, Priscila Goergen; STEIN, Lilian Milnistky. Compreendendo o Fenômeno das Falsas Memórias. In: STEIN, Lilian Milnistky. Falsas memórias: Fundamentos científicos e suas aplicações clínicas e jurídicas. Porto Alegre: Artmed, 2010.

REID, John; INBAU, Fred; BUCKLEY, Joseph; JAYNE; Brian. Criminal Interrogations and Confessions. $5^{\text {a }}$ Ed. Burlington: Jones \& Bartlett Learning, 2004.

SAAD, Marta. O direito de defesa do inquérito Policial. São Paulo: Revista dos Tribunais, 2004.

SCHOLLUM, Mary. Bringing PEACE to United States: A Framework for investigative interview. Police Chief Magazine, p. 30-37, 2017. 
SILVA, Inês Gonçalves Gomes Matos Silva. Falsas confissões e o contexto de investigação: A perspectiva dos investigadores. Dissertação de Mestrado em Psicologia Instituto Superior de Psicologia Aplicada (ISPA), Lisboa, 2008.

SILVA, Juliana Ferreira da. O plea bargain e as falsas confissões: uma discussão necessária no sistema de justiça criminal. Boletim IBCCRIM, São Paulo, v. 27, n. 318, p. 8-11., mai. 2019.

STEIN, Lilian; PERGHER, Giovanni Kuckartz; FEIX, Leandro da Fonte. Desafios da oitiva de crianças e adolescentes: técnica de entrevista investigativa. Programa Nacional de Enfrentamento da Violência Sexual Contra Crianças e Adolescentes. Disponível em: < https://bit.ly/32Mk3be>. Acesso em: 03/03/2020.

OLIVEIRA, Wellington de. Aplicando técnicas de entrevista e interrogatório na investigação - método Reid. Disponível em: <https://bit.ly/2Ys5Y0q> Acesso em: 06 dez. 2019.

PRADO, Geraldo Luiz Mascarenhas. Sistema acusatório. $3^{\mathrm{a}}$ Ed. Rio de Janeiro: Lumen Juris, 2006.

PRADO, Geraldo Luiz Mascarenhas. Prova penal e sistema de controles epistêmicos: a quebra da cadeia de custódia das provas obtidas por métodos ocultos. São Paulo: Marcial Pons, 2014.

TARUFFO, Michele. Uma simples verdade: o juiz e a construção dos fatos. Trad. de Vitor de Paula Ramos. São Paulo, Marcial Pons, 2012.

VARGAS, Joana Domingues. Em Busca da "Verdade Real”: Tortura e confissão no brasil ontem e hoje. Revista Sociologia e Antropologia. Rio de Janeiro, v. 2, n. 3, p. 237-265, junho, 2012. http://dx.doi.org/10.1590/2238-38752012v2310

ZAFFARONI, Eugenio Raúl. O inimigo do direito penal. Trad. Sérgio Lamarão. Rio de Janeiro: Revan, 2007. 


\section{Informações adicionais e declarações dos autores (integridade científica)}

Agradecimentos (acknowledgement): Gostaria de expressar minha gratidão aos colegas Raul Ariano Abramo, Helena Cabrera Oliveira e Luiza Restiffe, por todas as sugestões e comentários pertinentes. Ao João Henrique, pelo constante apoio.

Declaração de conflito de interesses (conflict of interest declaration): a autora confirma que não há conflitos de interesse na realização das pesquisas expostas e na redação deste artigo.

Declaração de autoria e especificação das contribuições (declaration of authorship): todas e somente as pessoas que atendem os requisitos de autoria deste artigo estão listadas como autores; todos os coautores se responsabilizam integralmente por este trabalho em sua totalidade.

Declaração de ineditismo e originalidade (declaration of originality): a autora assegura que o texto aqui publicado não foi divulgado anteriormente em outro meio e que futura republicação somente se realizará com a indicação expressa da referência desta publicação original; também atesta que não há plágio de terceiros ou autoplágio. 


\section{Dados do processo editorial}

(http://www.ibraspp.com.br/revista/index.php/RBDPP/about/editorialPolicies)

- Recebido em: 15/01/2020

- Controle preliminar e verificação de plágio: 19/01/2020

- Avaliação 1: 21/01/2020

- Avaliação 2: 22/01/2020

- Avaliação 3: 24/01/2020

- Avaliação 4: 29/01/2020

- Decisão editorial preliminar: 21/02/2020

- Retorno rodada de correções: 06/03/2020

- Decisão editorial final: 07/03/2020

\section{Equipe editorial envolvida}

- Editor-chefe: 1 (VGV)

- Editora-associado: 1 (MSG)

- Revisores: 4

\section{COMO CITAR ESTE ARTIGO:}

MOSCATELLI, Lívia Y. N. Considerações sobre a confissão e o método Reid aplicado na investigação criminal. Revista Brasileira de Direito

Processual Penal, Porto Alegre, vol. 6, n. 1, p. 361-394, jan./abr. 2020. https://doi.org/10.22197/rbdpp.v6i1.331

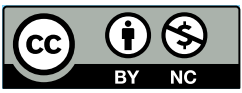

